\title{
EL CONCEPTO DE "PAZ"
} SEGÚN EL BUDISMO DEL SUTRA DEL LOTO: ANÁLISIS SOBRE LAS "PROPUESTAS DE PAZ" DE LA SOKA GAKKAI INTERNACIONAL (SGI) ENVIADAS A LA ONU

\section{Yanina Guthmann*}

Instituto de Investigaciones Gino Germani (IIGG) - Universidad de Buenos Aires / Recibido: 6 de noviembre de 2020 CONICET Aceptado: 21 de enero de 2021 $\bowtie$ yaniguth@gmail.com DOI: $10.46553 /$ colec.32.1.2021.p239-269

Resumen: En el marco de un creciente interés de las ciencias sociales por las minorías religiosas y su rol en los debates públicos, la Soka Gakkai Internacional (SGI) -organización budista laica, de origen japonés, surge como un objeto de estudio clave. A partir de herramientas del análisis textual y del discurso, en este artículo se estudian las "propuestas de paz" que envía la SGI cada año a la ONU, así como los presupuestos que subyacen a su escritura. En primer lugar, se constata la justificación de los envíos bajo el principio que la sociedad civil debería implicarse políticamente. Por otro lado, las propuestas se basan en una teoría de origen budista, el "humanismo del camino medio". Y el entrelazamiento de argumentos de orden religioso con argumentos científicos parece legitimarse en la ineficacia estructural de los organismos internacionales en la consecución de sus objetivos.

\footnotetext{
* Doctora en Ciencias Sociales (FSOC-UBA). Miembro de la carrera de investigador del CONICET con sede en el Instituto de Investigaciones Gino Germani (IIGG). Profesora carrera de abogacía (IUPFA).
} 
Palabras clave: SGI; budismo del Sutra del Loto; concepto de paz; implicación política; humanismo del camino medio; naturaleza humana

\begin{abstract}
In the context of a growing interest of social sciences for religious minorities and their role in public debates, Soka Gakkai International (SGI) - secular Buddhist organization, of Japanese origin, emerges as a key object of study. Using textual and discourse analysis tools, this article studies "peace proposals" that SGI sends to UN each year, as well as the assumptions underlying their writing. In the first place, the justification of these writings is legitimized under the principle that civil society should be political involved. On the other hand, proposals are based on a Buddhist theory called "middle way humanism." And the intertwining of religious arguments with scientific arguments could be explain by the structural inefficiency of international organizations in achieving their objectives.
\end{abstract}

Keywords: SGI; Sutra Del Loto Buddhism; Concept of Peace; Political Envolvment; Middle Way Humanism; Human Nature

A lo largo de la historia, personas de buena voluntad han encontrado severas persecuciones. Tal vez otras personas bienintencionadas hayan simpatizado secretamente con los propósitos de aquellas, pero, sin la capacidad de hacer nada al respecto, se han mantenido como observadores pasivos mientras las primeras resultaban derrotadas. Ya que la preservación personal es lo más importante en su modo de vida, tales observadores cuentan tan solo como elementos de una sociedad. No pueden ser la fuerza que la mantiene unida ni pueden prevenir su desintegración. (Daisaku Ikeda, Propuesta de Paz 2013, 2019 y 2020) 


\section{Introducción}

En el marco de un creciente interés de las ciencias sociales por las minorías religiosas y su rol en los debates públicos ${ }^{1}$, la Soka Gakkai Internacional (SGI), organización budista laica, de origen japonés, surge como un objeto de estudio clave (Ehrardt, Klein, Mc Laughlin y Reed 1995; Borhnholdt 2008 y 2009; Levi Mc Laughlin 2014 y 2018). En Argentina, el estudio de esta organización, su historia y sus prácticas, aparece en estudios de tipo antropológico y etnográfico (Welsch 2013 y 2018; Gancedo 2012 y 2015).

Antes de avanzar, es necesario aclarar algunos puntos respecto del carácter religioso y a la vez laico de la SGI -es decir que si bien se basa en una religión, el budismo del Sutra del Loto, no cuenta sin embargo, con entidad eclesiástica-. La SGI se presenta como una organización de budismo específica que se denomina hoy Budismo Soka. ${ }^{2}$ Esta rama del budismo refiere a prácticas, creencias e interpretaciones que son propias, y difieren de otras escuelas del budismo de Nichiren (ej. Nichiren Shoshu) y especialmente del resto del abanico budista. ${ }^{3}$ En este artículo no indagaremos en las controversias entre corrientes budistas, aunque si podemos afirmar que la SGI contribuyó enormemente a la difusión del budismo de Nichiren, que hasta mitad del siglo XX era casi desconocido o considerado como un budismo falso o ilegítimo y es además la organización más grande dentro de esta corriente; aunque siga siendo una entre varias. Según los debates realizados en el marco del PICT 4634-2016 se puede ubicar al budismo Nichiren en un espacio intermedio entre las religiones tradicionales y las espiritualidades de la Nueva Era, es una práctica que resalta el polo individual/espiritual- y a la vez mantiene cierta formalidad

\footnotetext{
${ }^{1}$ Ver en este aspecto, como contrapunto, la mirada crítica de Boltanksy (2004, 19-21) a la construcción del "espacio público" como sitio de debate y diálogo transparente.

${ }^{2}$ En este artículo nos referimos al Budismo Soka para mostrar la especificad de las posiciones de la organización y de su presidente honorario Daisaku Ikeda en la arena pública.

${ }^{3}$ Según Gancedo $(2012,49)$, “dentro de las multiples expresiones budistas se reconoce el Sutra del Loto o Budismo Nichiren". Nichiren es una figura bastante controvertida en la literatura sobre budismo y si bien es considerado el buda original por sus seguidores, hay muchas otras escuelas que no comparten esa opinión (Stone 1994).
} 
burocrática y convencional que permite la difusión de símbolos e imágenes comunes dentro de la organización colectiva de la práctica.

En este espacio intermedio, y desde 1981, la SGI fue reconocida como organización no gubernamental (ONG) para Naciones Unidas, marcando un vuelco de su misión hacia "la paz, la cultura y la educación" como pilares de acción. En líneas generales las propuestas que se envían desde el año 1983 a la ONU -una de las muchas acciones que la SGI realiza en la arena internacional ${ }^{4}$-, incluyen proyectos y denuncias en medioambiente, derechos de las mujeres, pobreza, movimientos populares, entre otros, desarrollando un concepto de paz amplio - positivo en el sentido de Galtung (1996; 2000). Sin embargo, más allá de la gran diversidad de temáticas tratadas, una de las cuestiones que se reiteran, es la de la eliminación de las armas nucleares y de las armas en general ${ }^{5}$ y el principio que de algún modo reúne a todas las propuestas puede resumirse en un "humanismo del Camino Medio". ¿Qué aporte específico hace la SGI a los debates contemporáneos sobre el concepto de "paz"? ¿Qué interés tiene estudiar estas propuestas para el análisis de la relación entre religión, activismo internacional y ciencias políticas?

${ }^{4}$ Otras actividades e iniciativas que se pueden mencionar son el establecimiento de instituciones de investigación sobre la paz, o investigaciones en temas de medioambiente, campañas de difusión en temáticas de derechos humanos, campañas de educación, exposiciones, entre otras acciones. Ver la página oficial https://www.sokaglobal.org/es/, la solapa "En la Sociedad".

${ }^{5}$ Uno de los temas centrales de las propuestas y también de la Soka Gakkai como organización, es la lucha por el desarme nuclear. El año 2017, año que ese conflicto se recrudeció, fue clave en la visibilización de este problema y la presencia de la SGI en la escena internacional también, ya que la Campaña Internacional para Abolir las Armas Nucleares (ICAN) basada en la declaración contra las armas nucleares recibió el premio nobel de la paz. Junto a las organizaciones que conforman ICAN, la SGI contribuyó en eventos, campañas, manifiestos y encuestas como socia internacional; y fue invitada como tal a la ceremonia de entrega del premio Nobel.

${ }^{6}$ Según Gancedo (2012) el origen del camino medio surge de Siddharta Gautama quien destacó a través de su propia experiencia "la inoperancia que tienen los sufrimientos corporales o las abstinencias estrictas - tan comunes en la rutina de ermitaños y gurúes - como parte de un camino espiritual haci la iluminación. En ese sentido llamó a su disciplina "el camino del medio", que ya que comprender un conjunto de rigurosas prácticas meditativas pero excluye las mortificaciones corporales del ideal ascético hindú" (Gancedo 2012, 47). 
La problemática de la paz en particular, resurge con fuerza en los años inmediatamente posteriores a la Primera Guerra Mundial. Partiendo del concepto de paz clásico (Kant [1795] 2002) hasta sus versiones más contemporáneas (Deutsch 1957; Doyle 1983; Russett 1993), se observa la ausencia del elemento religioso en los debates académicos. Philpott (2009) subraya la importancia que las ciencias políticas estudien con mayor profundidad a las religiones. Según este politólogo, hay un secularismo generalizado en los presupuestos de la disciplina, en los métodos, y este secularismo, puede implicar diferentes dimensiones, desde una connotación ideológica, prescriptiva como también hostilidad o neutralidad -la religión comparable con la superstición, la magia. De ahí, la idea de retomar el rol de las religiones en la vida social y en los debates públicos (Welsch 2014) más allá de la denuncia o mirada crítica respecto de sus peligros o derivas.

En el espacio público, muchas investigaciones subrayan cómo los actores religiosos clásicos apelan a discursos más cercanos a la ciencia y la filosofía, y proponen la idea de un "secularismo estratégico" e incluso una "onegeización" (Vaggione 2005). Estrategias similares se observaron en el caso del budismo de la SGI (Alves Pereira 2001; Bornholdt 2009; Welsch 2020). ${ }^{7}$ En este punto, un análisis de las propuestas se vuelve muy interesante puesto que el argumento religioso está presente y enlazado en el debate con citas de intelectuales, científicos y figuras históricas de la cultura occidental generando puentes y una intertextualidad muy particular entre mundo académico, político y religioso.

\footnotetext{
${ }^{7}$ Para dar un ejemplo, de la organización Soka Gakkai en Brasil, los investigadores analizan esta ambiguedad. En el caso de Bornholdt (2009) el análisis de los proyectos llevados a cabo por la SGI en Brasil muestran según la autora una ambigüedad en la que la importancia mayor da la difusión de la práctica más que al contenido de los proyectos en sí: reformas educativas, alfabetización de adultos, apoyo al cuidado del Amazonas. A nivel edilicio, muestra que la inversión mayor se da en los locales de difusión más que en los locales de debate y habla de estrategias de marketing. Y a nivel status la ambigüedad se manifiesta en un discurso público que la ubica como ONG pero que a nivel jurídico se encuentra inscripta como institución religiosa. Por su parte Alves Pereira, hay un esfuerzo deliberado para caracterizar a la organización como movimiento con aspiraciones a religión universal, pero hacia el público externo se marca un énfasis en el status de ONG reconocida por la ONU (Alves Pereira 2001, 195).
} 
A partir de herramientas del análisis textual y el análisis del discurso, en este artículo se analizan en primer lugar, las propuestas de paz en sí, su estructura y los principios que sustentan su envío anual a la ONU, en particular una invocación a la responsabilidad de la sociedad civil en el control de los gobiernos y los organismos internacionales, es decir una implicación de orden político. En una segunda parte, se analizan algunos aportes concretos respecto del concepto de "paz", en particular la idea que es necesario un anclaje a nivel "existencial" para que las propuestas y objetivos de organismos internacionales en relación con la paz -como la ONU-, dejen el mero plano teórico para ser una realidad cotidiana. A esta filosofía se la denomina "humanismo del camino medio" y conlleva en sí también una definición particular de la "naturaleza humana" que enlaza concepciones religiosas con concepciones de la filosofía política y del derecho, como, en particular, la idea de Justicia de Amartya Sen. ${ }^{8}$

\section{Las "propuestas de Paz" de la SGI como discurso y los principios que sustentan su envío anual a la ONU}

\section{II.1. La SGI: aclaraciones preliminares}

Según los relatos sobre su surgimiento, la organización Soka Gakkai Internacional (SGI) nace en 1930 como Soka Kyoiku Gakkai (Sociedad Educativa para la Creación de Valores). Fue fundada por Tsunesaburo Makiguchi, pedagogo y maestro primario crítico de la educación militarista que observaba en el Japón de principios del s. XX. Makiguchi encuentra en ese entonces, en la escuela budista de Nichiren Daishonin, la Nichiren Shoshu, -o Budismo del Sutra del Loto- el elemento matriz desde el que podía fundar un mejor sistema educativo basado en una "filosofía de los

\footnotetext{
${ }^{8}$ Según Sen, "Sin embargo, la filosofía también puede jugar un papel en aportar más disciplina y mayor alcance a las reflexiones sobre los valores y las prioridades tanto como sobre las frustraciones, opresiones y humillaciones que los seres humanos sufren a lo largo y ancho del planeta. Un compromiso compartido de las teorías de la justicia consiste en tomar en serio estos problemas y ver qué pueden hacer desde el punto de vista del razonamiento práctico frente a la justicia y la injusticia en el mundo" (Sen 2011, 446).
} 
Valores". 9 Se convierte a este credo y al proyecto, se une Josei Toda, también pedagogo y maestro primario, quien reconvierte dicha sociedad educativa en otra que con una acción social más amplia, con influencia en dimensiones como la económica y política. Toda decide también cambiar el nombre a lo que actualmente se llama Soka Gakkai focalizando la acción en el "aliento" al prójimo y en una transformación individual que se vincula a la invocación de Nam Myoho Rengue Kyo, sintetizando, la interpretación del Sutra del Loto predicada por Nichiren Daishonin. En 1960, dos años después de su muerte en 1958, lo sucede como tercer presidente de la Soka Gakkai, Daisaku Ikeda su discípulo y mano derecha desde los inicios de esta organización. Ikeda fue, desde el año 1960 y a través de viajar por el mundo, el promotor de la difusión global del Budismo de Nichiren además de ser considerado un referente social muy carismático. En 1975-26 de enero- se celebró en la isla de Guam (sur de India) una conferencia en la que se fundó la Soka Gakkai Internacional (SGI) de la cual Ikeda permaneció como presidente desde entonces. Con esta organización internacional se buscaba coordinar las actividades de las distintas representaciones institucionales fuera del Japón. En los años 70 las divisiones ideológicas con la Nichiren Shoshu, escuela budista de la cual Makiguchi se inspira, crecieron tanto que produjeron un sismo en $1991 .{ }^{10}$ En ese contexto la Soka Gakkai comienza a publicar las propuestas de paz, y se compromete también en el diálogo con diversas personalidades del s. XX (Mc Laughlin 2018,7) así como en la fundación de estructuras de investigación sobre la paz, el medioambiente y el arte.

II.2. Las "propuestas de Paz”, descripción general.

\footnotetext{
${ }^{9}$ Ver un análisis de la genealogía del Budismo del Sutra del Loto y de la Soka Gakkai en (Gancedo 2012).

${ }^{10}$ Según McLaughlin (2014, 6 y 7) en los años 70, el crecimiento de la membresía de la Soka gakkai en Japón forzó la fricción con el templo budista del que surge la Soka Gakkai: la Nichiren Shoshu. Las formas carismáticas de liderazgo de Toda e Ikeda no coincidían con la tradición del templo. En ese contexto, Ikeda fue forzado a dejar la presidencia de la organización en 1979. Sin embargo, en vez de marginarlo, este giro administrativo tuvo el efecto contrario, se intensificaron las conexiones afectivas entre él y sus adherentes, quienes lo veían como el verdadero representante del modelo de Nichiren.
} 


\section{II.2.1. Las temáticas de las propuestas}

Las propuestas que analizaremos en este artículo son textos envíados a la ONU cada 26 de enero. ${ }^{11}$ Las primeras propuestas son del año 1983 y siguen enviándose desde entonces y publicándose luego en la página de la SGI (con traducción en varios idiomas). No se realiza un análisis exhaustivo de las mismas en este trabajo pero se busca englobar los principios principales que las sustentan. ${ }^{12}$

Los títulos de las propuestas publicadas y accesibles en la web- a partir del año 2000- son muy diversos, lo que indicaría a priori que las temáticas incluidas en el concepto de "paz" son diversas también.

2020 La construcción de una era de solidaridad humana: Hacia un futuro para todos

2019 | Hacia una nueva era de paz y de desarme: Un enfoque centrado en las personas

2018 La construcción de un movimiento popular hacia una era de los derechos humanos

2017 | La solidaridad mundial entre los jóvenes: augura una nueva era de esperanza

2016 | El respeto universal a la dignidad humana: un gran camino hacia la paz

2015 | Un compromiso colectivo: erradicar el sufrimiento de la tierra y construir un futuro más humano

2014 |La creación de valor como factor de cambio global: construir sociedades sostenibles y resilientes.

2013 | Amor compasivo, sabiduría y valentía: por una sociedad global de paz y de coexistencia creativa

2012 | Seguridad humana y sostenibilidad: el respeto universal a la dignidad de la vida

\footnotetext{
${ }^{11}$ Se envían en esa fecha en honor a la conferencia de 1975 que se celebró en Guam, a través de la cual, la organización Soka Gakkai se internacionaliza y pasa a ser la Soka Gakkai Internacional (SGI) y se elige a Ikeda como su presidente.

12 https:/www.sgi.org/es/acerca-de-nosotros/propuestas-del-presidente-ikeda/
} 
2011 | Por un mundo de dignidad para todos: el triunfo de la vida creativa

2010 | Por una nueva era de creación de valores

2009 | Por la competencia humanitaria: una nueva corriente en la historia

2008 | Humanizar la religión para crear paz

2007 | La restauración de las conexiones humanas: el primer paso hacia la paz global

2006 | Una nueva era del pueblo: la creación de una red global de personas sólidas

2005 | Hacia una nueva era del diálogo: la exploración del humanismo.

2004 | La transformación interior: la creación de una corriente global por la paz

2003 | Una ética global de coexistencia: hacia un paradigma de "dimension humana" para nuestra época.

2002 |El humanismo del camino medio: la aurora de una civilización global

2001 | Cómo crear y sostener un siglo de la vida: el desafío de la nueva época

2000 | Reflexiones sobre una cultura de paz

Propuesta sobre abolición nuclear

2009 | Por la solidaridad mundial en aras de la abolición nuclear

Propuesta sobre la ONU

2006 | El fortalecimiento de la ONU: su misión ante el mundo (en inglés)

Propuestas sobre medio ambiente

2012 | Por una sociedad global sostenible: aprendizaje para el empoderamiento y el liderazgo

2002 | El desafío de un fortalecimiento global: educación para un futuro sostenible

En los títulos, algunos conceptos se repiten, "solidaridad", "desarme", "humanismo", "pueblo", "global", otros aparecen sólo una vez "ética", 
"compromiso colectivo". Hay conceptos que pueden rastrearse fácilmente en los escritos asociados a la religión budista clásica: "Amor compasivo", "sabiduría, "valentía", y al Budismo Soka: "creación de valor" y otros que surgen más bien del campo de las relaciones internacionales y de la política: "seguridad humana", "desarrollo sostenible", "movimiento popular".

Las propuestas se presentan como textos de quince mil palabras aproximadamente. Su diseño incluye un título que es el eje, y se desarrolla según temas sin numeración y sin índice, con un estilo ensayístico. Los textos presentan recuadros separados del texto, con datos duros, jurídicos, sociales e históricos. En todas, se citan obras académicas, literarias y ensayos -filosóficos o históricos, también muchos pies de página se dedican a citas de textos budistas. La tesis de Urbain (2009) analiza en detalle las propuestas y estudia en concreto la intertextualidad temporal entre diferentes etapas de las enseñanzas budistas: el Sutra del loto, predicado por Siddharta Gautama siglo quinto antes de Cristo, los goshos, que son cartas escritas por Nichiren Daishonin, monje japonés del Medioevo, y considerado el Buda original en el Budismo Nichiren, y que son una interpretación del Sutra del Loto, y las interpretaciones de estos escritos según Tsuneburo Makiguchi, Josei Toda y Daisaku Ikeda, "maestros" de la Soka Gakkai. ${ }^{13}$

En las propuestas se retoma estas diferentes etapas del pensamiento budista, así como también el pensamiento de distintos líderes de la lucha por la paz y los derechos humanos, - Mandela, Gandhi, Martin Luther King, Rosa Parks, Wangari Maathai, entre otros. Las propuestas en su discurso, toman a nivel disciplinario mucha influencia tanto de las relaciones internacionales y de las ciencias políticas, como también de la filosofía, la literatura y la teoría social -Hannah Arendt, Amartya Sen, Eric Hobsbawm,

\footnotetext{
${ }^{13}$ El concepto de "maestro" en el budismo soka es un concepto central ya que se refiere a la posibilidad de practicar correctamente las enseñanzas. El "maestro" o "sensei" es la única autoridad legitimada de interpretación de los textos originales, pero también la encargada de difundirlas (Welsch 2018). También respecto de la relación maestrodiscípulo se puede ver (Gancedo 2015).
} 
Carl Jung, Joseph Nye, John Dewey, Thomas Mann, André Gide, Ulrich Beck- entre otros. ${ }^{14}$

Según Verón (1987), los procesos de creación dejan marcas en los discursos, y el sentido, surge al manipular dichas marcas. En este trabajo no se analizará la lógica y contenido de cada una de las propuestas, ni los procesos de escritura, pero si características generales discursivas y textuales que permiten comprender principios que subyacen a su escritura y posterior difusión.

\section{II.2.2. Las "propuestas de paz" como "amonestaciones”}

Las propuestas están escritas en primera persona del singular, mostrando de algún modo el carácter individual y a la vez comprometido - ¿la implicación? del Presidente de la SGI, quien es el que firma cada una de ellas. El tono varía entre diversas formas verbales que varían en fuerza imperativa. Se verán algunos ejemplos de estas formas de discurso respecto del tema del desarme nuclear que vimos es central para la organización. En este punto en la página de la organización hay muchísimo material respecto de las consecuencias de las bombas de Hiroshima y Nagasaki. Estas investigaciones surgen los centros de investigaciones sobe la paz que son parte de la SGI como el Toda Peace Institute en Tokio. ${ }^{15}$

1) La propuesta:

En vista de que el año 2005 también marca el sexagésimo aniversario del lanzamiento de bombas atómicas sobre Hiroshima y Nagasaki, propongo que se realice una sesión especial de la Asamblea General de las Naciones Unidas, a la que asistan los jefes de estado y gobernantes del mundo, dedicada a la causa de la abolición nuclear. (Propuesta de Paz 2003)

\footnotetext{
14 Muchas referencias citadas son orientales y no están traducidas. Esta particular conexión entre literatura de Oriente y Occidente permite una riqueza poco común en las referencias y también en los ejemplos que brinda.

${ }^{15}$ Ver https://toda.org
} 
La consideración de los organismos internacionales y su responsabilidad en la concreción de la paz es un tema recurrente en las propuestas. También la inclusión y de todos los Estados y la posibilidad de diálogo.

2) La insistencia:

Más aún, quisiera insistir en esta sesión especial para discutir el establecimiento en la ONU de una nueva agencia especializada, para asegurar la estricta y efectiva implementación del desarme nuclear contenida en el artículo VI del TNP que data de 1968: "Cada parte en el Tratado se compromete a celebrar de buena fe negociaciones sobre medidas eficaces relativas a la cesación de la carrera armamentista nuclear en fecha cercana y a un tratado de desarme general y completo bajo estricto y efectivo control internacional. (Propuesta de Paz 2003)

En este punto, surgen propuestas concretas respecto a como los organismos internacionales podrían llevar a cabo la lucha por el desarme nuclear con la creación de agencias especializadas y dirigidas a objetivos concretos.

3) La exhortación:

El primer paso debe consistir en que los cinco estados que han declarado su armamento nuclear y que son, asimismo, los cinco miembros permanentes del Consejo de Seguridad cumplan con la responsabilidad asumida con el resto de las partes involucradas en el TNP, iniciando negociaciones de buena fe para concretar el desarme nuclear. Tengo la certeza de que lograr un acuerdo entre esas cinco potencias, para comenzar las negociaciones antes de la conferencia encargada del examen del TNP de 2005, o igualmente, realizar la sesión especial de la Asamblea General que propongo, pueden ser excelentes medios para terminar con el estancamiento actual. Exhorto a esos Estados, con la mayor firmeza, a elaborar un calendario de trabajo concreto para tratar la abolición nuclear. (Propuesta de Paz 2004)

Aquí es interesante observar la postura de la SGI frente a los Estados que forman parte de modo permanente del Consejo de Seguridad y la referencia a la responsabilidad que tienen como miembros de un organismo 
supranacional destinado a garantizar la paz, especialmente por ser justamente Estados nuclearmente armados. Esta exhortación, así como el resto de las recomendaciones permiten algunas reflexiones más generales.

Según Törnquist-Chesnier (2004), la participación de la "sociedad civil" fue incorporada por los propios organismos internacionales: estatuto consultativo en la ONU, procedimientos ad-hoc en las conferencias internacionales, etc. En este caso, es el saber religioso que entra en el terreno de lo político. La lógica redaccional de las propuestas se diferencia de los informes de las ONG's, de una consulta jurídica o de una decisión de una institución administrativa independiente. Se aleja del estilo judicial conciso; sin embargo, utiliza el presente del indicativo y mantiene cierto carácter prescriptivo. No hay un trabajo de neutralización de los intereses sociales a través de la formalización jurídica pero se busca la adhesión a partir de un lenguaje que conmueve: ¿una política de la compasión? (Boltansky 2004). ${ }^{16}$ La intertextualidad alcanza niveles que otros escritos no pueden alcanzar por las mismas reglas que los hacen definirse en su ámbito preciso. Su gran poder reside en la capacidad de unir referencias de Occidente y Oriente, referencias académicas, literarias y políticas en una coherencia discursiva plena: la de una filosofía ligada a una sabiduría milenaria. La diferencia entre un experto y un líder religioso es esta capacidad de lograr universalidad sin recurrir al único efecto de neutralización y universalización en los que caen los discursos formales y técnicos. El lenguaje de divulgación no deja de tocar los puntos centrales según el campo académico. El enunciador se vuelve la voz de la denuncia, pero también de la sabiduría.

\section{II.2.3. La ONU como destinataria de las Propuestas}

En la propuesta de 2006, la ONU aparece como un actor clave de la construcción de la paz, más allá de su evidente ineficacia, y esa idea se

\footnotetext{
${ }^{16}$ Para ulteriores análisis el trabajo de Boltansky puede resultar en un marco conceptual de análisis para las propuestas. Partiendo de las tesis de Arendt que diferencian la pena de la compasión, su análisis exhaustivo de las lógicas implícitas en las políticas humanitarias y en los discursos sobre la indignación y la denuncia resultan heurísticamente muy ricos, así como su análisis de la relación entre distancia y acción, la implicación moral y el espacio público.
} 
manifiesta concretamente en envío de las propuestas año tras año, así como en las referencias al organismo, a su funcionamiento y a los Estados miembros, en los textos mismos:

En varios aspectos, la ONU fracasó en conservar la paz en las cambiantes realidades de nuestro tiempo, y hay muchos obstáculos y críticas que la ONU aún no pudo trascender.(...) Sin embargo, mientras haya personas en este mundo que sufran, que vivan bajo amenazas y crisis, nosotros no podemos darnos el lujo de descartar el gran valor y misión de la ONU. (Propuesta de paz 2006, 2, mi traducción)

Creada en 1945, al finalizar la Segunda Guerra Mundial, la Organización de Naciones Unidas ONU, tuvo la misión de "mantener la paz y la seguridad internacionales" (ONU, 1945). La organización ha sido según los estudios de relaciones internacionales, la "cuna de los principales insumos conceptuales y materiales de la construcción de paz y es, en la actualidad, la organización internacional con el mayor número de oficinas encargadas de aspectos relacionados con este campo" (Rettberg 2013, 17). De algún modo, y más de sesenta años después de su creación, se puede observar que la ONU sigue dictando pautas normativas y tiene un poder de convocatoria difícil de equiparar más allá de sus efectos reales.

El objetivo de toda obra de argumentación es la de conquistar o fortalecer la adhesión de la audiencia (Perelman y Tolteca 1994). Y cuando la argumentación se organiza en función de la audiencia, es un modo de influenciarla. En este punto, se puede mencionar la cantidad de documentos producidos por Naciones Unidas, discursos, declaraciones y documentos que se citan en cada propuesta como forma de incluir su voz para luego recordarle a su vez, sus compromisos:

La ONU debe desempeñar un papel central en este esfuerzo. Como ha enfatizado el secretario general Annan, las Naciones Unidas se encuentran en una posición única para ayudar a crear estrategias amplias y sostenidas orientadas a erradicar el terrorismo. (Propuesta de Paz 2002, 11)

En ese sentido, las propuestas se montan en esta polaridad: se valida como el interlocutor y el referente más claro en el campo de la construcción 
de paz; al mismo tiempo que se marcan "los claros problemas que enfrenta en cuanto a la capacidad de decisión y ejecución” (Rettberg 2013, 19).

\section{II.3. El concepto de implicación política, en el Budismo del Sutra del Loto}

En la Propuesta de Paz de 2014, se presenta un fragmento que explica la importancia de implicarse políticamente y que de algún modo sustenta la acción de escribir a la ONU cada año. La filosofía budista en la que se basa la SGI es el budismo de Nichiren Daishonin. Este último propone en términos de responsabilidad frente a las circunstancias mundanas, refutar el escapismo, el negacionismo o el conformismo:

La filosofía budista que practican los miembros de la SGI exhorta a vivir con una clara conciencia de propósito, (...). Alienta a considerar el entorno inmediato como el escenario donde cada uno debe cumplir su misión en la vida, (...) Tres grandes corrientes de pensamiento. La primera de estas corrientes que rebatió Nichiren proponía un enfoque escapista de la realidad, Nichiren en cambio enseñó que el sitio donde debemos confrontar la realidad y transformar nuestra vida es el preciso lugar donde estamos en este momento. (...) La segunda forma de pensar que refutó Nichiren fue la que alentaba a las personas a negar la realidad. Esto producía una actitud de distanciamiento e indiferencia que encerraba a las gente en su mundo interior y la aislaba de las injusticias que ocurrían en el mundo real. Evitar o dejar de pensar en los problemas actuales, como si estos no existieran, no solo posterga la inevitable necesidad de resolverlos en algún momento futuro, sino que además los agrava aún más. La tercera forma de pensar que Nichiren denunció con enfoque estricto fue la que inducía a la gente a aceptar la realidad con resignación sumisa y pasiva, como si el statu quo, incluso en sus aspectos más inadmisibles e injustos, fuese algo imposible de modificar. (Propuesta de Paz 2014)

"Implicarse" en la realidad y actuar para transformarla, surgen entonces como principios rectores de esta filosofía. Desde el budismo, hay una relación entre los sujetos y su medio ambiente (esho funi). Esa relación e interdependencia incluye la responsabilidad del pueblo de manifestarse frente a los gobernantes cuando observan que sus decisiones no son las 
correctas en términos de dignidad humana. Para apoyar esta idea se cita a Arendt, filósofa que en su análisis sobre la auténtica humanitas, se refirió al tema de no dejarse atrapar por las situaciones sino, a la inversa, transformarlas creando de manera activa nuevos vínculos y por lo tanto, brinda una primera herramienta para implicarse en esta realidad:

En referencia al concepto de aventurarse en la vida pública, desarrollado por Karl Jaspers, quien también fue su mentor, Arendt argumenta que la humanitas nunca se alcanza en soledad, sólo quien aventura su vida y su persona en la vida pública puede adquirirla. Esta aventura sólo es posible sobre una confianza en los seres humanos. Una confianza en, y esto aunque es fundamental es difícil de formular, lo humano de todos los seres humanos. De otro modo no se podría. [Arendt, Ensayos de comprensión 1930-1945] (Propuesta de paz 2017, 18)

La forma de responsabilidad de la que se habla, incluye entonces una dimensión de la confianza y los vínculos. ¿En qué sentido las acciones de la SGI en su dimensión de institución religiosa pueden entonces relacionarse con las formas más institucionalizadas o tradicionales de "acción política" que la misma organización desarrolla? Para empezar a contestar esta pregunta, se podría comenzar analizando la implicación política de los jóvenes miembros japoneses en el Komeito, partido político que nació en los años 60 a partir de la Soka Gakkai bajo el lema de partido limpio considerado como un partido de base popular- y que se convirtió en el tercer partido de la Cámara legislativa - aunque por una serie de situaciones conflictivas en los años 70 tuvo que separarse formalmente de la organización religiosa (Mc Laughlin, 2014; 2018). ${ }^{17}$ Por otro lado, habría

${ }^{17}$ Se produjeron críticas al Komeito atacando su naturaleza poco democrática o igualitaria en la selección de los candidatos. También se realizaron referencias al art. 20 sobre la prohibición de ejercicio de la autoridad política por una organización religiosa más allá de la existencia de una garantía constitucional de libertad de asociación y creencias religiosas. También hubo un incidente conocido como "Incidente Osaka" en el que un grupo de miembros intentaron comprar votos y hasta 1962, año en que se comprobó que no había pruebas de que la orden hubiera sido dada desde la organización central, Ikeda fue también envuelto en una demanda judicial (McLaughling 2014, 61- 65). 
también una raíz profunda que une la política al Budismo del Sutra del Loto y que fue a su vez motivo de numerosos estudios académicos (Ehrardt, Klein, McLaughlin y Reed 1995; Fisker-Nielsen 2012). Para contextualizar lo anterior, se puede volver a este texto de Nichiren dónde se explicita la obligación de los ciudadanos de implicarse en política $-\mathrm{O}$ de implicarse moralmente en la vida pública- y cómo la SGI se posiciona frente a este postulado que a su vez se inspira en la propia vida del monje-Buda en el que “amonestar" al Estado es un práctica central (Stone 1994, 238-240). ${ }^{18}$

\section{II.4. El Tratado para el Establecimiento de la Paz en la Tierra - El Rissho Ankokuron}

En el 1279 Nichiren Daishonin redacta un tratado amonestando al gobierno que reinaba en ese entonces en Japón e insistiendo con la devoción al Sutra del Loto como única enseñanza válida y superando la lealtad al Estado y al gobernante (Stone, 1994, 234). Esta amonestación trajo como consecuencia persecuciones políticas e incluso lo lleva a una condena a muerte por parte del gobierno. Este tratado publicado en español (Daishonin, 2008, 6-33) explica que tanto los desastres en política internacional (guerras e invasiones) como los desastres naturales (ciclones y pestes) derivan del accionar humano y de las creencias que estos sostienen en su fuero interno.

En lo últimos años, ha habido raras perturbaciones en los cielos, acontecimientos extraños sobre la tierra, pestes y hambrunas en cada rincón del imperio, que se extienden al resto del país. A lo largo de los caminos yacen bueyes y caballos muertos, y en las avenidas se apilan los huesos de los difuntos. La muerte se ha llevado a más de la mitad de los habitantes, y cuesta hallar a alguien que no deplore la situación. (...) Con los limitados recursos que están a mi alcance, me puse a analizar esta cuestión en profundidad, y a leer algunas escrituras en busca de respuestas. El pueblo

\footnotetext{
${ }^{18}$ Ciertas formas -por ejemplo las propuestas como amonestaciones- pueden vincularse con una apelación a Nichiren y a que sus acciones puedan pensarse como una estrategia más amplia de legitimación de las prácticas actuales de SGI como herederas de la tradición de Nichiren.
} 
de hoy vuelve las espaldas al bien y jura lealtad al mal. (...) Por eso, debe modificar enseguida los principios que abriga en su corazón y abrazar el único vehículo verdadero, la única buena doctrina (del Sutra del loto). (Daishonin 2008, 6, 7 y 28)

Este principio budista entonces, el de la relación entre las creencias humanas y el entorno, "la unidad entre el sujeto y el medioambiente" (esho funi) es central. A partir de este principio es que surge la importancia de manifestar a los decisores, cuando las creencias no son las correctas, las causas reales de los problemas y de marcar la necesidad de transformar de raíz ciertas situaciones. Por otro lado, según los análisis de Stone, Nichiren fue la figura paradigmática de la resistencia a la imposición de una religión política en la era de Kamakura (1185-1333) a través del "riguroso exclusivismo" del Sutra del Loto (Fisker-Nielsen, 236, mi traducción). Según Stone, este exclusivismo que en la época de Nichiren representaba una posibilidad de encontrar otra fuente de legitimidad que permitiera una resistencia al gobierno, fue variando luego de la muerte de Nichiren. Según McLaughlin (2014, 51 y 57), este exclusivismo era la estrategia elegida para salvar en ese momento al pueblo de Japón, y se lograba a través del shakubuku, técnica de conversión proactiva. En este sentido, el análisis de la implicación de los jóvenes de la Soka Gakkai en Japón en política permite de algún modo medir la importancia de esta línea de acción y principio de la organización. Según Fisher-Nielsen $(2012,2)$, Japón se suele asociar a una cultura dominada por ideologías conservadoras y normas sociales que afectan a un consenso social homogéneo y a una identidad nacional fuerte estructuras sociales muy rígidas-. Su trabajo de investigación entre 2003 y 2004 muestra que sólo una parte de los practicantes de la Soka Gakkai en Japón se implica en el partido Komeito, sin embargo el partido responde a un principio fundamental de la organización según el cual no sólo hay que mejorar las condiciones personales a través de cambios en las conductas y en los pensamientos sino que también las condiciones sociales más amplias, y se sostiene en la idea que los seres humanos, a nivel fundamental, tienden a la nobleza y a la solidaridad (Fisher-Nielsen 2012, 58). 


\section{El concepto de "paz" según el Budismo Soka y el "humanismo del camino medio"}

\section{III.1. Breve repaso de los debates actuales sobre la Paz}

A nivel conceptual y teórico la problemática de la paz, puede pensarse a partir del clásico la Paz Perpetua de Kant, y los trabajos que retoman y actualizan sus ideas principales en las que el Estado es el actor central (Doyle 1983; Russett 1993; Habermas 1996).

El ideal cosmopolita desarrollado por Kant en "La paz perpetua", publicado en 1795, conserva hoy en día una indiscutible vigencia. Originalmente en su formulación, este ideal estaba profundamente enlazado con la necesidad de descubrir los medios apropiados para superar el estado de guerra en el que la historia humana se había instalado. Kant plantea tres propuestas para alcanzar dicho fin: una constitución republicana, la instauración de una federación de Estados libres y la creación de un derecho cosmopolita. Kant considera que la paz es posible por ser necesaria.

Para resumir, según Kant la paz perpetua se consigue si, primero, se da un pacto entre Estados republicanos que deciden abandonar el estado de libertad salvaje imperante para formar una comunidad pacífica en la cual ninguno de los entes políticos pierde su soberanía porque ellos mismos, así reunidos, son la autoridad máxima que los regula y controla. Se trata, por ende, de una decisión racional vinculada con la concepción de un derecho de gentes que no debe permitir un derecho de guerra, pues es este recurso, justamente, el que se intenta dejar atrás. Esta federación de paz pone entonces fin a cualquier guerra.

Según Habermas si bien es cierto que los fundamentos filosóficos de la obra de Kant se han problematizado y ha habido un cambio en el marco histórico, lo cual ha hecho necesaria una reformulación, es cierto también que los objetivos propuestos permanecen vigentes una gran medida (Habermas 1996). En esta línea, Doyle (1983) desarrolla el legado de Kant a nivel de las relaciones internacionales distinguiendo niveles y dimensiones en el pensamiento liberal mostrando su capacidad heurística hoy. Russet (1993) por su parte, desarrolla la idea de una paz democrática a nivel histórico y sus transformaciones y potencialidades en la actualidad. 
Finalmente, el desarrollo académico de los temas relativos a la paz se intensifica en el siglo XX con las grandes guerras. En los años inmediatamente posteriores a la Primera Guerra Mundial, se desarrolla una disciplina, que con el tiempo vendría a denominarse "Investigación para la paz y Resolución de Conflictos" en la que los Estados ya no son los únicos actores relevantes. El común denominador de estos debates contemporáneos - que se refleja en la multiplicidad y heterogeneidad de los programas y estrategias que han adoptado organizaciones nacionales, internacionales, públicas y privadas - es, sin embargo, que no hay consenso sobre el significado de la palabra "paz": cuáles son las condiciones suficientes para generar las bases de una paz duradera o para evitar que los conflictos se reanuden.

La tajante dicotomía entre el minimalismo como ausencia de homicidios y el maximalismo que equipara la paz a un profundo cambio social no refleja en la actualidad, como lo hacía hace una década, las principales posturas del debate. Según Rettberg, el debate se ubica actualmente en torno a "los grados de profundidad de los cambios requeridos y a la utilidad de distinguir entre lo que es necesario para la paz y lo que es necesario para el desarrollo" (Rettberg 2013, 10). En este punto hay una diversidad de actores implicados: instituciones y organismos relativos a la disminución o fin de la violencia, a la reconstrucción de infraestructura, a temáticas de transición política, desarrollo económico, reformas sociales, recuperación o fortalecimiento del Estado de derecho, fortalecimiento de la sociedad civil y desarrollo de la acción humanitaria; así como acerca del orden en el que se deben adelantar cada una de estas metas. También son distintas en cuanto a la perspectiva temporal de su actividad y a qué tan ambiciosas son en cuanto a su definición de (construcción de) paz. Algunas han desarrollado su capacidad de respuesta en el corto plazo, sobre todo a nivel humanitario y temporalmente limitada, mientras que otras intervienen con estándares temporales más amplios.

La SGI, en las propuestas se ubicaría del lado de los estándares temporales amplios (generacional) y a su vez presentaría un sentido de paz amplio y maximalista sin dejar de lado sugerencias, exhortaciones, puntuales en el corto plazo. Por otro lado, sostendría como Kant la posibilidad de una paz perpetua pero no en base solamente a la democracia o a principios liberales en relación al Estado. En la postura del budismo 
Soka se integran elementos existenciales ligados a una concepción más social de la "naturaleza humana" y a una crítica a la racionalidad instrumental. En el próximo apartado se desarrollará con más detalle. Lo que sustenta esta definición de paz, es una filosofía basada en el "humanismo del camino medio" que define de algún modo el poder y el conocimiento en un sentido muy distinto a las posiciones realistas en política internacional. ${ }^{19}$

\section{III.2. El "humanismo del camino medio" como vía para la paz: un discurso} ético en el marco de un debate político filosófico

En la Propuestas de Paz 2015, Ikeda, explica que la palabra "política" deriva del griego politeia que, entre otros significados, denota el papel de los ciudadanos en el Estado. Por su parte, se explica que en japonés el vocablo correspondiente a "economía" es la abreviatura de un término chino de cuatro caracteres que significa "generar orden en la sociedad y aliviar el sufrimiento del pueblo" (Propuesta de Paz 2015).

Según esta Propuesta, cuando se hace excesivo hincapié en los resultados numéricos, tanto en la política como en la economía, se suele prestar atención insuficiente a las necesidades de la gente real, lo cual debilita la motivación necesaria para lograr los objetivos deseados. Según Ikeda:

(...) la obsesión por los índices macroeconómicos y las tasas de crecimiento a menudo relegando a un segundo plano la preocupación por la vida, la dignidad y la subsistencia de los individuos; de tal suerte el ritmo febril y acelerado de la actividad económica no consigue aliviar la lucha que afronta la población cotidianamente. Cuando la política funciona en gran escala se observa una tendencia que se ha definido como "déficit democrático" según la cual la voluntad popular no se ve reflejada en las medidas y acciones políticas. El fenómeno correspondiente en el ámbito de la economía serían los excesos del sector financiero, que permiten a la

19 El realismo en política internacional (Hans Morgenthau, Kenneth Waltz) es una escuela de pensamiento que presupone que los actores son racionales y que sus motivos y capacidades durante un conflicto no cambian, así como las ventajas que podrían derivar si el conflicto se evitara. 
especulación incontrolada causar estragos en la economía real. (Propuesta de Paz 2017)

Ahora bien ¿Cómo sería humanizar la política y la economía desde la perspectiva budista? Citando a Gandhi, la propuesta de 2017, proclama que a la hora de tomar decisiones hay que recordar el rostro de la persona más pobre y débil que uno haya conocido y preguntarse si la medida que estamos por adoptar le será de algún provecho a esa persona. La repetición sostenida de este proceso nos permite explorar más profundamente el significado y la función de los sistemas políticos y económicos, y crear las condiciones sociales que den lugar a su rehumanización. Este es el dinamismo esencial del Camino Medio:

Una idea fundamental que propone el budismo es la noción del Camino Medio. Si pensamos en ello relacionándolo con el concepto del nyaya, el Camino Medio indica una atención cuidadosa y permanente a las consecuencias que nuestros actos tienen en la vida de los demás, tomando como criterio universal la cuestión del sufrimiento o la felicidad humana. (Propuesta de Paz 2017, 12)

Este "camino medio" no es el camino medio de la filosofía helénica exactamente, sino que parece de algún modo un tipo de reflexividad orientada hacia la solidaridad con los sectores y personas más vulnerables y que exige flexibilidad, alejándose de posturas tradicionales en política. El "humanismo del Camino Medio" permite entonces formular una concepción diferente de la sociedad y de los fenómenos sociales sin por tanto negar el valor de cada corriente de pensamiento, pero poniendo en tela de juicio el idealismo que las caracteriza:

Las diferentes corrientes de pensamiento de la sociedad tienden a ser, por lo general, restrictivas y exclusivistas. Por ejemplo, el liberalismo postula conceptos taxativos, que se oponen a las ideas socialistas y las contradicen. Lo mismo cabe afirmar con respecto a las ideologías socialista y comunista. El materialismo, por su parte, rechaza el espiritualismo, y viceversa. Ni siquiera los principios artísticos escapan a la regla. (...) Sin embargo, la filosofía de inspiración budista que propone la Soka Gakkai 
no exige uniformidad. Por el contrario, trata de comprender las condiciones de la época y, a partir de allí, extrapolar las mejores opciones. Este es el primer aspecto que quiero destacar del humanismo del Camino Medio: que capta la relatividad y la mutabilidad de todas las cosas. (...) El segundo punto que me gustaría recalcar es la importancia de establecer una autonomía basada en comprender el verdadero aspecto de las cosas. Cuando hablo de autonomía -o autodisciplina-- me refiero a la capacidad de ser protagonistas de la propia vida, manteniendo una genuina independencia y autodeterminación, en medio de la evolución caleidoscópica que caracteriza la realidad fenoménica. (...) Esto me conduce al tercer aspecto que me gustaría analizar: el humanismo del Caminos: Medio es capaz de penetrar hasta las capas más profundas de la naturaleza humana, sepejdonde encuentra la rica veta de las cualidades universales que comparten todos losis piphombres y mujeres. Así pues, este camino no excluye a nadie y abarca a todas las personas, por el solo hecho de pertenecer al género humano. (Propuesta de Paz 2002, 6-8)

En este punto se ven tres movimientos, abandonar la rigidez de los pensamientos dogmáticos, captar la fluidez y complejidad de la realidad, propagar la idea de autonomía. Esta autonomía por otro lado, no es la autonomía del pensamiento liberal clásico, como individualismo sino como humanismo, es decir en la comprensión de lo que une a las personas. En este punto, la noción de identidad permite avanzar un paso más en la comprensión de la dignidad humana según esta filosofía. ${ }^{20}$ En este punto,

${ }^{20}$ Según Ikeda: "En la India, el budismo surgió en respuesta a la pregunta universal de cómo confrontar las realidades del sufrimiento humano y ayudar a quienes están atrapados en ese sufrimiento (...) Shakyamuni nunca tuvo el propósito de reflexionar pasivamente sobre la evanescencia de la vida y lo inevitable de los sufrimientos (...) En su necedad, los mortales comunes, aunque ellos mismos van a crecer y no podrán evitar envejecer, al ver que los demás llegan a la ancianidad y declinan, comienzan a cavilar sobre ello, se angustian por ello y experimentan vergüenza y odio, sin siquiera pensar que están ante su propio problema, y afirmó que otro tanto era cierto respecto de nuestras actitudes hacia la enfermedad y la muerte. La preocupación de Shakyamuni siempre fue la arrogancia interior que nos hace considerar objetos a las personas y aislar a quienes sufren por la vejez y la enfermedad. Por ende, fue incapaz de hacer caso omiso de quienes padecían dolencias en soledad o de los ancianos que eran separados de la sociedad" (Propuesta de Paz 2013, 4 y 5). 
las propuestas citan la teoría de la justicia Amartya Sen (2009) y esta puede ser un buen marco de análisis de la filosofía del budismo Soka: la importancia de las vidas humanas y sus experiencias más allá de las instituciones en la definición de las prácticas democráticas y la definición de racionalidad como rational choice.

En la Propuesta de Paz 2013, se menciona la idea de "resistir a la manipulación de la piscología de masas y las instigaciones a la violencia que provocan los conflictos" con la idea de prevenir las tragedias. Se cita a Amartya Sen su libro Identidad y Violencia:

La insistencia, aunque solo implícita, en una singularidad no elegida de la identidad humana no solo nos empequeñece a todos, sino que hace que el mundo se torne mucho más inflamable (...) En cambio la principal esperanza de armonía en nuestro mundo atormentado reside en la pluralidad de nuestras identidades, que se cruzan entre sí y obran en contra de las profundas separaciones a lo largo de una única, tajante y resistente línea de división que supuestamente no es posible atravesar. (Propuesta de paz 2013, 9)

Por último, si bien niega que la violencia sea inevitable en el ser humano, esta filosofía no la niega. En la Propuesta de Paz 2013, se cita el Manifiesto de Sevilla sobre la violencia, redactado por un equipo internacional de especialistas y adoptado por la UNESCO en 1989 que sostiene "científicamente es incorrecto decir que la guerra o cualquier otra forma de comportamiento violento está genéticamente programada en la naturaleza humana." También afirma: "científicamente es incorrecto decir que la guerra es un fenómeno instintivo o que responde a un único móvil" (Propuesta de paz 2013, 7). En esta misma propuesta, Ikeda, dice:

Coincido plenamente con la declaración. Y sin embargo, aún debemos superar numerosos impedimentos si deseamos terminar con los ciclos de conflicto y de violencia. Para ello, debemos comenzar por preguntarnos qué es lo que precipita a los seres humanos a la guerra y a la destrucción. (Propuesta de Paz 2013, 8) 
Es decir que, si bien la violencia no es parte de la naturaleza humana, sí hay una raíz en lo humano que la habilita. Sin aceptar este origen es imposible eliminar según la concepción budista, el ciclo de violencia. La naturaleza humana y carácter fluctuante puede explicarse por la teoría de los "diez estados" de los seres humanos: "Estos conceptos expresan de manera concisa las perspectivas budistas esenciales sobre la naturaleza de la vida y del vivir. El budismo clasifica en diez categorías o "estados" las experiencias vitales que se suceden a cada instante. En orden ascendente, de las menos a las más deseables, esas categorías son: Infierno, Hambre, Animalidad, Ira, Tranquilidad, Éxtasis, Aprendizaje, Comprensión Intuitiva, Bodhisattva e Iluminación. El estado de Iluminación -o Budeidad- es la forma ideal de vivir, caracterizada por un inmenso caudal de benevolencia, coraje y sabiduría (Propuesta de Paz 2002, 5 y 6).

En esta línea de pensamiento, es importante distinguir algunos niveles en el concepto de violencia que circulan en las teorías contemporáneas sobre la paz. Según Harto de Vera, hay una diferencia entre violencia latente y manifiesta, sea directa o estructural. ${ }^{21}$ La violencia latente es algo que está presente pero no aparece fácilmente (Harto de Vera 2016, 136). Buscar entonces el origen y la raíz de la violencia es una estrategia para la paz. (Hueso García 2000, 129).

Sin caer en una concepción antropológica "optimista" o "pesimista" (Harto de Vera 2016, 143), la visión budista del ser humano lo considera como potencial y esencialmente un buda con una responsabilidad completa tanto de transformar y perfeccionar su personalidad, como el mundo que lo rodea. Coincide entonces con la visión de la "paz imperfecta" (citada por Harto de Vera 2016, 140) y tomada del investigador Francisco Muños, donde "se maneja una antropología que trata de dar cuenta de la complejidad del ser humano tratando de contemplarlo como una criatura en la que están presentes y conviven en una relación conflictiva, agónica y contradictoria

21 Es interesante retomar aquí las distinciones entre violencia "indirecta" o "estructural", y la idea de "violencia directa". Según López Becerra, basándose en la teoría de Galtung: "nos referiremos al tipo de violencia donde hay un actor que comete la violencia como "personal" o "directa", y a la violencia donde no hay tal actor como "estructural" o "indirecta". También existiría una "violencia cultural", ligada a religión, derechos, ideas (...)" (López Becerra 2011, 89). 
tanto los elementos descritos por la corriente optimista como por las posiciones pesimistas" (Harto de Vera 2016, 143).

Según Galtung e Ikeda, para pensar la posibilidad de justicia y paz, "debemos ser realistas en nuestras mentes y mantener viva la flama del idealismo en nuestros corazones" (2007). La filosofía religiosa, en este caso el budismo del Daishonin, puede entonces anclar a nivel existencial propuestas teóricas; puede a su vez recuperar los mitos fundamentales que explican la raíz de la no discriminación entre los seres humanos y darle mayor profundidad al concepto de dignidad. Una noción de dignidad que se redefine desde una perspectiva social en el contacto con los otros seres humanos. Ikeda se apoya en la filosofía de Arendt en este punto. Por mucho que nos afecten las cosas del mundo, por muy profundamente que nos estimulen, "sólo se tornan humanas para nosotros cuando podemos discutirlas con nuestros semejantes" (Propuesta de paz 2013, 9). Ese deseo mantiene encendida la llama de la dignidad humana (Propuesta de paz 2016).

Aquí se puede relacionar esta visión del budismo Soka con las referencias al concepto de "amistad" en el campo académico de la resolución de conflictos: se une esta dimensión más íntima con lo social e incluso con lo político. Según Hoef y Oelsner (2018), la difusión de la amistad como práctica social, construida por gestos, actos simbólicos políticos, prácticas repetitivas, y otros actos discursivos y hechos institucionales, puede crear un clima emocional positivo para la paz. En este sentido, la socióloga Elise M. Boulding (2000) también rescata la importancia de las celebraciones como rituales que humanizan y reafirman los valores sociales.

\section{A modo de conclusión}

En la definición kantiana de dignidad, el hombre es un fin en sí mismo, no un medio para usos de otros individuos. La raíz de la concepción moderna de la dignidad humana, es entonces la autonomía moral. Ésta, a su vez, implica una concepción activa de la libertad humana, puesto que cuando nos damos ley, nos autodeterminamos. En este punto, habría una dignidad inherente y específica a los seres humanos que trasciende sus 
diferencias. El budismo del Sutra del Loto coincide con esta visión: la dignidad no depende de la clase social y trasciende las diferencias de cualquier tipo. Sin embargo, plantea una nueva forma de pensarla en el plano social.

La "filosofía del humanismo del camino medio" se puede asimilar en parte a la crítica de Simmel (2014) a la ética kantiana, en la relación entre el deber ser y el ser. Propone un concepto de "dignidad" que no puede ser abstraído de la experiencia humana, sin que eso, signifique renunciar a su centralidad.

La postura de la SGI respecto de la paz se nutre entonces del budismo del Sutra del Loto y se apoya en los debates del mundo académico, científico y literario. En esa intertextualidad radica el valor del material: la calidad de las citas y la integración de las referencias. Elegir a la ONU como destinatario también tiene un profundo significado en términos de reconocimiento de su rol, pero también como una búsqueda de acercamiento a los focos de visibilidad internacional (soft power) y tomar una postura de observación crítica.

Frente a los debates en torno al carácter de ONG u entidad religiosa de la SGI, respecto al discurso que utiliza y sus repertorios de acción, se puede primero afirmar que la SGI es una ONG acreditada por la ONU y eso no la deshabilita como entidad religiosa. El prejuicio contra lo religioso, impregnado de siglos de fundamentalismos y opresiones eclesiásticas tiene sentido. Sin embargo, analizar las propuestas en detalle nos abre a una mirada ética sobre lo político que muchas veces se vuelve urgente. La libertad discursiva de las propuestas resulta muy rica como objeto de estudio en el marco de los actuales debates en torno a la paz. Las propuestas evalúan el impacto de las creencias religiosas en la historia de la humanidad, es decir aplica en cierto sentido, a sí misma el "humanismo del camino medio". En este sentido, la capacidad reflexiva es muy amplia y se replantea inclusive, el rol mismo de la religión. Según Kazuo Watanabe, en la Propuesta de Paz de 2008:

La segunda reforma religiosa debe ser emprendida por un nuevo Lutero, un nuevo Calvino. Aunque pueda resultar una expresión curiosa, el único camino posible es la humanización de la religión. Quiero decir con ello que hay que descartar todos los aspectos de la religión que ofuscan el juicio y 
reconocer que incluso Dios existe para servir a la humanidad. Debemos reflexionar sobre la pequeñez y la fragilidad humanas que rápidamente nos convierten en instrumentos y esclavos de aquello que creamos. Es necesario enseñar esto a los demás y hacerse cargo de la tarea de esclarecer nuestra responsabilidad con todo lo que los seres humanos hemos conquistado desde el renacimiento.” (Propuesta de Paz 2008, 6)

En un contexto de emergencia de nuevos actores y repertorios de acción, el activismo de las minorías religiosas en el ámbito internacional merece ser objeto de investigación en ciencias sociales. También dado lo acuciantes que se vuelven las temáticas relativas a la paz y la inercia de muchos espacios tradicionales de poder - puede pensarse este tipo de discursos como una fuerza ética no necesariamente religiosa ni partidaria.

\section{Referencias}

Alves Pereira, Ronan. 2001. "O budismo leigo da Sôka Gakkai no Brasil: da revolução humana à utopia mundial”. Tese apresentada ao Departamento de Antropologia do Instituto de Filosofia e Ciências Humanas, da Universidade Estadual de Campinas, sob a orientação do Prof. Dr. Guillermo Raul Ruben. Campinas SP.

Boltansky, Luc. 2004. Distant suffering, morality, medias and politics. Cambridge: Cambridge University Press.

Bornholdt, Suzana. 2008. "Japanese Buddhism and Social Action: the case of Soka Gakkai in Brazil”. Revista Nures 10.

—. 2009. "ONG ou religião? O caso da Soka Gakkai no Brasil". Ciencias Sociales y Religión/Ciências Sociais e Religião 11 (11): 181198.

Boulding, Elise. 2000. Cultures of Peace. Syracuse: Syracuse University Press.

Boutros-Ghali, Boutros. 1992. An Agenda for Peace: Preventive Diplomacy, Peacemaking and Peace-Keeping (A/47/277-S/24111). Naciones Unidas. Recuperado de http://daccess-ddsny.un.org/doc/UNDOC/GEN/ N92/259/61/PDF/N9225961.pdf

Daishonin, Nichiren. 2008. Los escritos de Nichiren Daishonin, Soka 
Gakkai. Barcelona: Herder Editorial. Disponible en https://www.nichirenlibrary.org/es/

Deutsch, Karl. 1957. Political Community and the North Atlantic Area: International Organization in the Light of Historical Experience. Princeton: Princeton University Press.

Doyle, Michael W. 1983. "Kant, liberal legacies and Foreign affairs". Philosophy \& Public Affairs.

Ehrardt, George, Axel Klein, Levi McLaughlin y Steven R. Reed. 1995. Komeito, Politics and Religion in Japan. Institute of East Asian Studies, University of California, Berkeley.

Fisker-Nielsen, Mette. 2012. Religion and Politics in Contemporary Japan. Soka Gakkai Youth and Komeito. USA y Canada: Routledge.

Galtung, Johan. 1990. "Cultural violence”. Journal of Peace Research 3 (27): 291-305.

1996. Peace by Peaceful means: Peace and Conflict, Development and Civilization. London: Sage.

Galtung, Johan y Carl G. Jacobsen. 2000. Searching for Peace: The road to transcend. London: Pluto Press.

Galtung, Johan y Daisaku Ikeda. 2007. Scegliere la pace. Milano: Esperia.

Gancedo, Mariano. 2012. "La práctica del budismo Nichiren en la ciudad de Buenos Aires (Argentina)". Miológicas XXVII: 47- 60.

—. 2015. "Rostros de una diáspora. Comunidad japonesa y religiosidad en la Soka Gakkai Internacional (Argentina)". Horizontes antropológicos 43: 183-210.

Grasa, Rafael. 2010. “Cincuenta años de evolución de la investigación para la paz, tendencias y propuestas para observar, investigar y actuar". Recerca p. Pau. Oficina de Promoción de la Paz y de los Derechos Humanos, Generalitat de Cataluña, Barcelona.

Habermas, Jurgen. 2005. La paix perpétuelle, Le bicentenaire d'une idée kantienne. Paris: les editions du Cerf.

Harto de Vera, Fernando. 2016. "La construcción del concepto de paz”. Cuadernos de Estrategia 183: 119-146

Hueso García, Vicente 2000. "Johan Galtung, la transformación de los conflictos por medios pacíficos". Cuadernos de estrategia 111: 202-226. 
Ikeda, Daisaku. Propuestas de Paz 2000-2018. Disponibles en https://www.sgi.org/es/acerca-de-nosotros/propuestas-del-presidenteikeda/

Kant, Immanuel. (1795) 2002. La paz perpetua. Madrid: Alianza.

López Becerra, Mario H. 2011. "Teorías para la paz y perspectivas ambientales del desarrollo como diálogos de imperfectos". Revista Luna Azul 33: 85-96.

McLaughlin, Levi. 2014. "Electioneering as religious practice. A history of Soka Gakkai's political activities to 1970". En Komeito. Politics and Religion in Japan., editado por George Ehrhardt, Axel Klein, Levi McLaughlin y Steven R. Reed. Berkeley: Institute of East Asian Studies, University of California.

- 2018. Soka Gakkai's Human Revolution: The Rise of a Mimetic Nation in Modern Japan. University of Hawai'i Mano Kahualike. UH Press Book Previws.

Organización de Naciones Unidas (ONU). 1945. Carta de las Naciones Unidas. Recuperado de: http://www.un.org/ spanish/aboutun/charter.htm

Perelman, Chaim y Lucie Olbrechts-Tyteca. 1994. Tratado de la argumentación. Madrid: Gredos.

Philpott, Daniel. 2007. "Explaining the Political Ambivalence of Religion”. American Political Science Review 101 (3): 505-525.

Rettberg, Angelika. 2013. "La construcción de paz bajo la lupa: una revisión de la actividad y de la literatura académica internacional". Estudios Políticos 42: 13-36.

Russett B. 1993. Grasping the democratic peace. Princeton University Press: New Jersey.

Sen, Amartya. 2011. La idea de la justicia, Buenos Aires: Taurus. Simmel, Georg. 2014. Intuición de la vida. Buenos Aires: Prometeo.

Stone, Jacqueline. 1994. "Rebuking the Enemies of the Lotus. Nichirenist exclusivism in Historical Perspective". Japanese Journal of Religious Studies 21 (2-3): 231- 259.

Törnquist-Chesnier, Marie. 2004. "Expertise et éthique dans la fabrication $\mathrm{du}$ droit international public: la contribution des organisations non gouvernementales: trois cas d'étude". Tesis de doctorado bajo la dirección de Devin G. Paris: IEP. 
Urbain, Olivier. 2009. “Daisaku Ikeda's Philosophy of peace: hauman revolution, dialogue and global civilization". Tesis. University of Bradford. Disponible en https://philpapers.org/rec/URBDIP-2.

Vaggione, Juan M. 2005. "Reactive politicization and Religious Dissidence: The politial mutations of the religious". Social Theory and Practice 31 (2): 233-255.

Van Hoef, Yuri y Andrea Oeslner. 2018. "Friendship and Positive Peace: Conceptualising Friendship in Politics and International Relations". Politics and Governance 6: 115-124.

Verón, Eliseo et al. 1987. El discurso político. Lenguajes y acontecimientos. Buenos Aires: Edicial.

Welsch, Daniela. 2014. "Budismo: felicidad de uno, prosperidad de la sociedad. El carácter transformador de la práctica budista en la Soka Gakkai Argentina". XI Congreso Argentino de Antropología Social, Rosario.

2018. "Passing on the Law. The Growth of Soka Gakkai International in Argentina". International Journal of Latin American Religion.

2020. "Los espacios de la Soka Gakkai: Hacia la construcción de un budismo humanista". ESPACO E CULTURA, UERJ 47:140-164. 